$$
\text { H A R VAR D }
$$

\title{
The Value of Corporate Citizenship: Protection
}

Dylan Minor

Working Paper 16-021 


\title{
The Value of Corporate Citizenship: Protection
}

\author{
Dylan Minor
}

Harvard Business School

Working Paper 16-021 not be reproduced without permission of the copyright holder. Copies of working papers are available from the author. 


\title{
The Value of Corporate Citizenship: Protection*
}

\author{
Dylan Minor \\ Harvard Business School
}

August 2015

\begin{abstract}
We explore the notion that corporate citizenship, as obtained through Corporate Social Responsibility (CSR), is used by managers to protect firm value, helping their firm better withstand negative business shocks. We formally explore two parallel mechanisms for such protection - one of building moral capital (CSR Contributions) and another of improving investor posteriors (CSR Investments). We find some theoretical and empirical support for both of these, but in different settings. In particular, we find that firms with higher CSR Investments enjoy an average of $\$ 1$ billion of saved firm value upon an adverse event. In contrast, CSR Contribution firms lose value (on average) upon an event, possibly due to disingenuous contributions. Meanwhile, due to managerial moral hazard, firms with high levels of CSR Contributions face adverse events more often, whereas those with high levels of CSR Investments face them less often.
\end{abstract}

JEL: G30 G32 G39

${ }^{*}$ Corresponding Author: Dylan Minor dminor@hbs.edu. The author would like to thank Ernesto Dal Bo, Rui de Figueiredo, Daniel Diermeier, Bryan Hong, John Morgan, Orie Shelef, Steve Tadelis, and Terry Taylor for their helpful comments. Also thanked are the seminar participants at Northwestern, UC Berkeley, University of Maryland, University of Michigan, and Wharton. 
Keywords: Corporate Governance, Corporate Social Responsibility, Reputation, Moral Capital 
"There is one and only one social responsibility of business - to use its resources and engage in activities designed to increase its profits..." Milton Friedman

"Corporate social responsibility is best seen as the management of risk, as the avoidance of damages to the company's reputation." Financial Times, July 7, 2004 .

There are a plethora of past studies examining the relationship of a firm's financial performance to its level of corporate social responsibility (CSR). In short, the studies at best show there is a nominal relation between the two (see Elfenbein (2007) for an extensive survey). If CSR does not provide any financial benefit, in the spirit of Friedman (1970), it seems that managers should then spend their time and efforts in other areas that are expected to actually enhance firm value. Indeed, Institutional Shareholder Services (ISS), an MSCI brand, admonishes investment managers in their "2011 U.S. Proxy Voting Guidelines Summary" to often vote against CSR type initiatives in order to "protect shareholder value."

Nonetheless, CSR seems increasingly important to at least some investors, as many companies now report annually on their social performance, and independent organizations such as KLD Analytics provide regular corporate accountability reporting. CSR also seems increasingly important to managers; a survey by the Economist magazine ${ }^{1}$ reports some $56 \%$ of managers consider CSR as a "high" or "very high" priority. Further, the Economist reports $87 \%$ of firms now have a formal CSR program in place. Echoing firm sentiment, some MBA program ranking schemes now include a standalone category for CSR.

This all suggests that there must be some aspects of CSR that are valuable. In this spirit, the Economist reports that while only some $6.5 \%$ of managers report that CSR increases revenue, most managers claim they instead use CSR to secure a brand and rep-

\footnotetext{
${ }^{1}$ January 7 th, 2008
} 
utation. They summarize it in this way:

"Most of the rhetoric on CSR may be about doing the right thing and trumping competitors, but much of the reality is plain risk management. It involves limiting the damage to the brand and the bottom line that can be inflicted by a bad press and consumer boycotts, as well as dealing with the threat of legal action."

Economist, January 7,2008

Thus, in practice, it seems that there is a belief that a primary value of CSR is to protect a firm's value. In this paper, we explore this important notion both theoretically and empirically.

There are at least two leading theories of CSR as protection. Godfrey (2005) develops an informal model of protection where firms engage in voluntary philanthropic acts to build a reservoir of goodwill (i.e., "moral capital") from which to draw upon during an adverse event. An alternative mechanism proposed by Minor and Morgan (2011) is that protection comes from improving the posteriors of investors. In particular, those firms that engage in CSR activities related to an adverse event are given more of the benefit of the doubt concerning their negligence related to the event. For example, if a firm engages in substantive (positive) environmental CSR, should it become involved in an environmental disaster, as a result of Bayesian updating, it is less likely the firm is guilty of negligence, reducing its expected event cost.

We formalize both of these theories to develop sharper and contrasting empirical predictions. While both predict protection of firm value upon an event, there are also important differences. First, Godfrey (2005) predicts firm protection comes from a firm contributing to philanthropic activities, which are generally not related to a particular adverse event. In contrast, Minor and Morgan (2011) argue that protection only comes from engaging in 
those activities that are related to such an event. Second, after we extend both of these theories by considering what happens to the incident rate of different types of firms, we see further differences. In particular, those firms building moral capital should experience increased incident rates due to moral hazard: being assured of some increased protection encourages some managers to be less careful in avoiding a disaster. In contrast, protection as portrayed in Minor and Morgan (2011) is derived from being more conscientious, and thus incident rates for these protected firms should be lower.

We also complement the extant literature by introducing disingenuous builders of moral capital. In Godfrey (2005), all actors and activities are transparent. However, in a world where managers might act strategically, some can choose to free-ride on the positive image of building moral capital by superficially engaging in CSR. The net result of such firms is that we should observe diminished protection, if not increased costs, from engaging in CSR.

The notion of participating in CSR to protect firm value is related to a growing literature on firm self-regulation. In early work, Maxwell et al. (2000) extend the economic theory of regulation by adding voluntary actions by firms to reduce pollution under the shadow of regulation. Maxwell and Decker (2006) show this force also operates in the other direction: voluntary actions can reduce regulation intensity. This activity helps firms engaging in voluntary actions by means of reduced regulation and therefore expected cost. Baron (2010) adds that such self-regulation can also arise from altruistic managers. Whatever the source of self-regulation, it can increase firm value. In fact, Mackey et al. (2007) argue that even voluntary actions that are costly in expected value terms can add firm value with sufficient investor demand for such actions. Thus, this paper complements this stream of literature by exploring yet another potential benefit of self-regulation: Those self regulation activities categorized as CSR can also help protect firm value during adverse events. 
In terms of empirical work on protection by means of CSR, Godfrey et al. (2009) test the moral capital idea in Godfrey (2005) by conducting an event study on 178 "opportunistically drawn" firm events. They find that from the set of firms that they select to study, those that are engaging in philanthropic focused activities enjoy a reduced loss in firm value when facing regulatory and legal actions against them. However, firms engaging in more profit-centric CSR do not enjoy such protection. Similarly, Jacobs et al. (2010) also find that philanthropic gifts provide positive firm value. In contrast, Hillman and Keim (2001) find just the opposite: engaging in CSR for primary stakeholders (i.e., profitcentric CSR) increases firm value whereas engaging in CSR for secondary stakeholders (i.e., philanthropic) decrease firm value.

In terms of negative CSR, Capelle-Blancard and Laguna (2010) study stock market reactions to 64 chemical plant and refinery explosions. They find that those firms with poor environmental records are punished more harshly. If we count voluntary pollution abatement as CSR, we find that positive CSR also hurts firm value. Fisher-Vanden and Thorburn (2011) show that firms that increase participation in voluntary emissions reduction lose firm value. Similarly, Jacobs et al. (2010) find that self-disclosed increases in environmental performance yield a reduction in firm value. Lyon et al. (2013) find a nuance in the consequences of positive CSR for firms in China: the penalty for positive CSR diminishes when firms are state-owned or in high-polluting industries. We complement these works by formalizing and testing mechanisms that can generate and reconcile these conflicting findings.

With theoretical predictions in hand, we then explore the CSR activity of large US public companies from 1991 through 2012. We find that those firms engaged in CSR related to adverse events enjoy substantial protection - an average of close to $\$ 1$ billion of protected firm value - and also lower event rates. In contrast, we observe that firms 
that engage in philanthropic CSR unrelated to incidences face events more often and do not enjoy protection from their CSR efforts. In fact, in some cases, they are even further punished upon an event.

We see this paper's contribution as twofold: First, it is the first paper to formalize and contrast possible mechanisms that generate protection from CSR, an important and primary motivation of managers to engage in CSR. In doing so, we extend the theory by considering incident rates as a way to distinguish between mechanisms. We also introduce disingenuous firms within the moral capital framework, which identifies those cases where moral capital building might fail to protect firms. Second, using a novel dataset covering 22 years, that is to our knowledge the largest of its kind, we document for the first time the relation of CSR to event incident rates. We are also able to identify those cases where CSR provides protection and shed some light on when CSR actually can help or hurt firms upon an event.

The balance of the paper is organized as follows: In the first section we present a unifying model of CSR as protection, formalizing both Godfrey (2005) and Minor and Morgan (2011) in a single model. The next section provides an empirical analysis and the final section provides a concluding discussion. All proofs are relegated to the appendix. 


\title{
1 Protection through Corporate Social Responsibility
}

\author{
Managers choose $e, \mathbf{t} \quad$ Nature chooses event/no event(s)
}

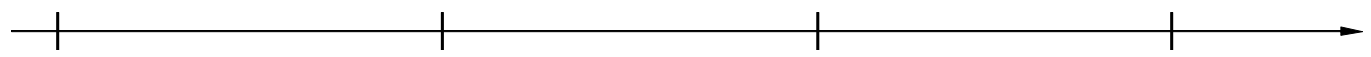

Nature chooses high/low risk state Firms with events are revalued

We begin with a simple model of CSR to illustrate and contrast the two mechanisms of firm value protection. The first mechanism, which we call CSR Investments, works through affecting the posteriors of investors, as proposed in Minor and Morgan (2011). The second mechanism, which we call CSR Contributions, works through the firm building a reservoir of goodwill from which to draw upon should the firm face an event, as proposed in Godfrey (2005).

\subsection{The Model}

Assume managers of each firm type choose their level of CSR activities as well as direct effort to manage business risk, where risk is the risk of an adverse event. We abstract away from any agency problems and assume managers maximize firm value. The above diagram provides the timeline of the game. Managers make two CSR level decisions: whether or not to invest in operational CSR (i.e., CSR Investments) and whether or not to contribute to charitable CSR (i.e., CSR Contributions). Formally, we denote these CSR choices as a vector $\mathbf{t}=\left(t_{C}, t_{w e}\right)$, where $t_{j} \in\{H, L\}$ for $j \in\{C, I\} . H(L)$ denotes a hightype (low-type) firm. ${ }^{2}$ We assume that CSR type is reported through CSR reporting and

\footnotetext{
${ }^{2}$ It is straightforward to extend the analysis to more than two types on each CSR dimension. However, we restrict the choice to two types since this is sufficient to illustrate the forces at work and eases exposition.
} 
is thus publicly observed. The element $t_{C}\left(t_{I}\right)$ denotes a firm's binary choice of CSR Contribution (Investment). While it costs zero for a firm to be a low-type, choosing to be a high-type costs a firm $c_{j}$. CSR cost is the realization of a privately observed random variable having support $[0, \infty)$ over an atomless distribution function $F_{j}(\cdot)$. For simplicity assume that draws from $F_{C}(\cdot)$ and $F_{I}(\cdot)$ are IID across and within firms.

A manager also chooses a level of effort $e \geq 0$, which is unobservable. Manager effort helps keep a firm from an undesirable outcome, as explained below. Effort costs are increasing and convex. For simplicity, suppose that the cost of $e$ units of effort is $C(e)=\frac{1}{2} e^{2}$. Thus, whereas $c_{j}$ is a fixed cost to engage in higher CSR, $C(e)$ is the ongoing cost of responsibility.

The combination of CSR activity and managerial effort determine the business risk state $\theta \in\{h, l\}$ of the firm. If an adverse event occurs while the firm is operating in a high risk state, it will prove more costly than if it is in a low risk state, as discussed below. With probability $\gamma_{t_{I}} e$ the low risk state is realized, while the high risk state occurs with complementary probability. The parameter $\gamma_{t_{I}}$ represents the influence of CSR investment activity on the business risk state, where $0<\gamma_{L}<\gamma_{H}$. In other words, CSR Investment reduces the chance of being in the high risk state. Following the state realization, nature then determines whether an adverse event occurs. With probability $p_{\theta}$ an event occurs in state $\theta$, where $0<p_{l}<p_{h}$. That is, events are less likely to occur if the firm is operating in the low risk state than in the high risk state. Note CSR Contributions do not affect the return to effort in keeping a firm out of a high risk state. Hence, a firm with or without CSR Contributions can have either $\gamma_{L}$ or $\gamma_{H}$.

Stakeholders (e.g., investors and regulators) only observe whether an event, E, has occurred and the firm's level of CSR Investment (i.e., and thus $\gamma_{t_{I}}$ ) and CSR Contribution. Since a manager's effort is unobservable, stakeholders must make an assessment of the 
likelihood that the firm was operating in a high risk state conditional on an event occurring.

Define

$$
\rho(\mathbf{t})=\operatorname{Pr}[\theta=h \mid E, \mathbf{t}]
$$

That is, $\rho(\mathbf{t})$ denotes the (equilibrium) beliefs of stakeholders that the firm was in the high risk state conditional on an event occurring and the firm's level of CSR activity. A firm triggering an event from a high risk state can be thought of as having been "at fault," whereas if the event was triggered from a low risk state the firm is not "at fault." A firm then suffers loss $K$, scaled by the stakeholders' belief $\rho(\mathbf{t})$ that the firm was operating in a high risk state. That is, being "at fault" is more costly than not being "at fault." However, this loss upon an event is tempered by the firm's potential building of moral capital. As explained in Godfrey (2005), through a CSR Contribution a firm builds a reservoir of goodwill that can either provide an increased benefit of the doubt or lessen the stakeholder-induced penalty upon a bad event (or both). We capture this potential benefit by the expression $\left(\frac{1}{M I_{t} C R_{C}+1}\right)$ in equation (2). Increased moral capital $M$ means an increased benefit upon an event.

To summarize, the expected profits of a firm with private cost parameters $c_{j}$ choosing public CSR types $t_{j}$ and private effort $e$ are

$$
\pi(c, t, e)=\pi_{0}-\sum_{j} c_{j} I_{t_{j}=R_{j}}-\frac{1}{2} e^{2}-\left\{\left(1-\gamma_{t} e\right) p_{h}+\gamma_{t} e p_{l}\right\}\left(\rho(t) K\left(\frac{1}{M I_{t_{C}=R_{C}}+1}\right)\right) .
$$

Here, $I_{j}$ is an indicator function which equals one if the manager chooses a high level of CSR Investment (and) or Contribution. I denote status quo profit $\pi_{0}$. In short, expected profit is then status quo profit, minus the total cost of CSR, minus the cost of effort, minus the unconditional expected cost of an event. 
To summarize the various states, Figure 1 provides a schematic for all of the possible outcomes:

[Figure 1 here]

There exist unique values $\left(e_{L}^{*}, e_{H}^{*}\right)$ corresponding to the equilibrium effort of a firm. To see the claim regarding $\left(e_{L}^{*}, e_{H}^{*}\right)$, notice that for given a $t_{c}$, the optimal effort choice for a manager of firm type $\mathbf{t}$ is a globally concave problem having as its solution:

$$
e_{\mathbf{t}}^{*}=\gamma_{t_{I}}\left(p_{h}-p_{l}\right)\left(\rho(\mathbf{t}) K\left(\left(\frac{1}{M I_{t_{C}=R_{C}}+1}\right)\right)\right) .
$$

To close the model, it remains to determine equilibrium beliefs. Recall that stakeholders know a firm's type and can thus deduce its equilibrium effort. Hence, from Bayes' rule, upon an event, stakeholders hold belief

$$
\rho(\mathbf{t})=\frac{\left(1-\gamma_{t_{I}} e_{\mathbf{t}}^{*}\right) p_{h}}{\left(1-\gamma_{t_{I}} e_{\mathbf{t}}^{*}\right) p_{h}+\gamma_{t} e_{\mathbf{t}}^{*} p_{l}} .
$$

Thus, any equilibrium effort levels given $t_{c}$ simultaneously solve

$$
\begin{aligned}
& e_{L}^{*}=\gamma_{L}\left(p_{h}-p_{l}\right)\left\{\frac{\left(1-\gamma_{L} e_{L}^{*}\right) p_{h} K}{\left(1-\gamma_{N} e_{L}^{*}\right) p_{h}+\gamma L e_{L}^{*} p_{l}}\left(\frac{1}{M I_{t_{C}=L_{C}}+1}\right)\right\} \\
& e_{H}^{*}=\gamma_{H}\left(p_{h}-p_{l}\right)\left\{\frac{\left(1-\gamma_{H} e_{H}^{*}\right) p_{h} K}{\left(1-\gamma_{H} e_{H}^{*}\right) p_{h}+\gamma_{H} e_{H}^{*} p_{l}}\left(\frac{1}{M I_{t_{C}=H_{C}}+1}\right)\right\} .
\end{aligned}
$$

The optimal pair of $t_{I}$ and $t_{C}$ chosen is then simply a function of comparing profits from $e_{L}^{*}$ and $e_{H}^{*}$ given each $t_{C} \in\{H, L\}$. In equilibrium, there exists some $c_{I}^{*}$ such that when fixing the choice of $t_{C}$, we have the same level of profit whether that manager chooses her firm to be a low (L) or high (H) type 


$$
\pi\left(0, L, e_{L}^{*}\right)=\pi\left(c_{I}^{*}, H, e_{R}^{*}\right)
$$

This can readily be seen by noting $\pi(\cdot)$ is strictly decreasing in $c_{j}$ and $\pi\left(0, H, e_{R}^{*}\right)>0$ while $\pi\left(c_{I}, H, e_{R}^{*}\right)<0$ as $c_{j} \rightarrow+\infty$. By similar argument, when fixing the choice of $t_{I}$, there is some $c_{C}^{*}$ such that the manager is indifferent between choosing $t_{C} \in\{H, L\}$.

This analysis provides the first proposition:

Proposition 1 Fix $t_{C}$. In equilibrium, managers of high-type (low-type) firms exert effort $e_{H}^{*}\left(e_{L}^{*}\right)$ as given in (5) and face CSR cost $c_{I} \leq c_{I}^{*}\left(c_{I}>c_{I}^{*}\right)$, where $c_{I}^{*}$ solves equation (6).

We next need a Lemma to prove our propositions concerning changes in firm values upon an event and incident rate of events.

Lemma 1 Fix $t_{C}$. In any equilibrium, $\gamma_{L} e_{L}^{*}<\gamma_{H} e_{H}^{*}$.

What this Lemma tells us is that if we compare two firms that are the same on the dimension of CSR Contribution $t_{C}$, even though the high-type firm has a greater return to effort, it will still produce enough effort such that $\gamma_{L} e_{L}^{*}<\gamma_{H} e_{H}^{*}$. This yields an important empirical prediction, as this inequality is necessary for the CSR investing firm to be less likely to have an event, as shown in the next proposition.

Proposition 2 Compared with CSR Investment low-type firms, CSR Investment high-type firms have events less often and lose less value upon an event.

The intuition of the above proposition is with CSR Investment, the manager essentially internalizes the cost of an adverse event and increases her effort to reduce it. This increased effort both reduces the chance of an event and also reduces the change in firm value upon an event because investors now consider it less likely the event was caused by negligence. 
This proposition then provides two key predictions that we can test in the data while holding CSR Contribution level constant: increased CSR investment level both reduces the event incident rate and reduces the loss of firm value upon an event. The next proposition considers the parallel case of changes in levels of CSR Contributions, holding a given CSR Investment level constant.

Proposition 3 Compared with CSR Contribution low-type firms, CSR Contribution high-type firms have events more often and lose less value upon an event.

The intuition for this proposition is that when a firm is provided a reservoir of goodwill to draw upon during an adverse event, this induces moral hazard on behalf of the manager. That is, due to the goodwill protection, she now puts in less effort since an adverse event will prove less costly. Consequently, the firm's incident rate is increased. As far as we are aware, this is a novel finding; the extant literature stresses the protection value of goodwill building upon on an event. However, there has been no discussion of how this can induce moral hazard. Nonetheless, even with such moral hazard, the firm still enjoys a net protection benefit upon an event; as shown in the appendix, the positive effect of the goodwill reservoir dominates the negative effect of this increased chance of negligence. This last proposition also reveals that comparing incident rates as a function of the type of CSR (i.e., Contribution versus Investment) can help us disentangle the sources of protection from CSR.

\section{Empirical examination}

\subsection{General strategy}

The empirical setting is product markets where the event is a product recall. These events are often seen by the investment committee as a potential shock to a firm's value and 
reputation due to their signaling nature (Davidson and Worrell (1992) provide a review of past product recall literature. See also Hartman (1987) for a hedonic model treatment of recalls). These types of events are arguably more exogenous than some events studied in the extant literature, such as choosing to join a CSR organization (e.g., Fisher-Vanden and Thornburn (2011)) or disclose one's intention to increase CSR (e.g., Jacobs et al. (2010)).

Our empirical strategy has two facets. First, we will test if firms engaged in CSR Investment (CSR Contributions) have a lesser (greater) incident rate. Second, we then test if those firms engaged in each type of CSR experience a lesser loss in firm value upon an event. I begin by reviewing the data characteristics and then turn to the event study methodology and regression model.

\section{$2.2 \quad$ Data}

The Data consist of three components. The first part is the abnormal returns of various firms during our product recalls, which we describe in detail in the next section. The event returns are then merged with Compustat, the second set of data. For firm control data of the S\&P 500 firms we have: annual sales ("Sales (net)"), asset value ("Assets-total"), market value ("common shares outstanding" $\times$ "price-calender year-closing"), and percent of profits per share ("EPS (Basic) - Exclude Extra. Items " $\div$ "price-calender year-closing"). Actual product recall events were obtained by hand collection of product recall events of S\&P 500 firms as indexed by the Wall Street journal from 1991 through 2012. Although this categorization of product recalls is certainly not perfect, it is the primary source used by past product recall literature. Further, we wanted to have an ex-ante fixed criteria of selecting recalls to prevent subjective inclusion or exclusion on the part of the researcher. We do note that recalls included in the Wall Street Journal press announcements are biased towards larger event recalls. However, the theory predicts that it is these large scale recalls 
where we will see the effects, if any exist.

Occasionally some firms had more than one event announcement in a year, most often a later press announcement related to the same event. For the data collection, we simply summed the abnormal returns together, following the methodology as shown below, by summing abnormal returns over event window days. Having more than one event in a year for a given firm occurred for only 25 of the firm/ event years, and these were almost exclusively for automobile companies.

The final component of data is corporate accountability reporting from KLD Analytics, owned my MSCI. KLD is a main source of CSR research for socially responsible investing firms. Nelson Information's Directory of Investment Managers reports that these types of investing firms hold approximately $11 \%$ of all managed assets. KLD's data have been commonly used in past related academic studies (see Chatterji et al. (2007) for a review). KLD conducts proprietary research to assign annual CSR ratings to publicly held firms across various dimensions, including product markets. Their CSR ratings began in 1991, making it one of the oldest corporate accountability reporting sources. We use data from 1991 though 2012.

To match our theoretical predictions, we need to use a measure of CSR that is related to the event and another CSR activity that is not. In this spirit, we use CSR ratings on the dimensions of product markets and community reputation to respectively represent these activities. The former then captures the notion of investment in issue-related CSR (i.e., CSR Investments) and the latter proxies for the contribution of moral capital (i.e., CSR Contributions).

CSR reputation in product markets (i.e.,CSR Investments) can be thought of as a firm's superior reputation earned from the conscientious creation, marketing, and distribution of its products. "Good" CSR will mean that a firm typically embraces superior 
quality assurance procedures in the development and production of its products, conducts ethical marketing campaigns, provides products with extra social value, provides products to disadvantaged demographic groups, and generally faces product recalls voluntarily. In contrast, "Bad" CSR means that firms are usually involved in regulation fights, suffer safety violations, accept lower product safety standards, and conduct limited due diligence on their supply chain.

Community CSR (i.e., CSR Contributions) can be thought of as the extent to which a firm positively impacts its surrounding communities. Examples of "Good" community CSR are giving a meaningful portion of income to charity, maintaining an exceptional employee volunteer program, or supporting local housing and education needs. Examples of "Bad" community CSR might include being involved in projects considered to have a negative economic impact on the local community, not respecting local indigenous people in the firm's operation decisions, or being involved in major local tax disputes.

For both kinds of CSR, we categorize firms into three types, as follows. The lowest type, which we will call "Low" types, are involved in "Bad" things for the given type of CSR. The next type, "Medium" types, are not involved with "Bad" things, but neither are they involved in "Good" things - they are simply responsible corporate citizens. Finally, there are some exceptional firms that not only avoid being involved in "Bad" things, but are also participating in some extra "Good" things. We dub these "High" types. We include a full summary of "Good" and "Bad" types of CSR used by KLD in the appendix.

Table 1 reports the summary statistics for our primary variables. As can be seen, roughly $7 \%$ (13\%) of firm-years a firm will earn a High Product (Community) reputation. Meanwhile, some $74 \%$ (80\%) of firm-years fall in the middle of being classified as high on the dimension of Product (Community) CSR. The balance of firm-years are considered "Low" types. Now we consider our first primary theoretical prediction concerning event 
rates.

[Table 1 about here]

\subsection{The Risk of Incident}

Recall, our propositions predict that firms with high Product CSR should have lesser event incidence rates, whereas those firms with high Community CSR should have greater event incidence rates. To test these predictions, since possible outcomes are only zero or one, we use a logit random-effects panel regression. ${ }^{3}$ We specify our full regression as

$$
\operatorname{Pr}\left(y_{i t}=1 \mid \mathbf{X}_{i t-1}, \boldsymbol{\gamma}, \beta, \alpha_{i}\right)=\Lambda\left(\alpha_{i}+{ }_{i}+\beta C S R_{i t-1}+\mathbf{X}_{i t-1}^{\prime} \boldsymbol{\gamma}+\mathbf{Y}_{t}^{\prime} \boldsymbol{\delta},\right)
$$

where $\alpha_{i} \sim N\left(0, \sigma_{\alpha}^{2}\right)$. The variable $C S R_{i, t-1}$ contains CSR ratings for firm $i$ based on the previously defined CSR typologies. The vector $\mathbf{X}_{i, t-1}$ contains financial controls, as outlined in the section (2.2), and also industry controls. Finally, the vector $\mathbf{Y}_{t}$ contains year dummies.

With this regression, we can ask a simple question: is it the case that CSR reputation - either in terms of CSR Investments or CSR Contributions - is related to incident rates as theory predicts? Table 2 reports the results of this regression. Column (1) provides the baseline regression, which includes year fixed effects but not financial and industry. We find, as predicted by theory, high-type firms involved in building moral capital through Community CSR are more likely to have an adverse event. For Product CSR, as consistent with theory, high-type firms are less likely to have an adverse event. Even after including

\footnotetext{
${ }^{3}$ Note that it is not feasible to utilize a conditional fixed-effect logit model since identification requires dropping all firms that never experience an event (i.e., $93.5 \%$ of all observations are dropped).
} 
all of our discussed controls, the coefficient estimates for either high-type of firm are still significant at the $1 \%$ or $5 \%$ level.

If we extend our main theory to medium-type firms, these firms should have the same direction of estimated effect as high-type firms, but the effects should be attenuated. For Community CSR, high-type Community CSR firms have greater estimated coefficients. A Wald test of equality of the high- and medium-type Community CSR coefficients yields a $\chi^{2}=24.83(\mathrm{p}$-value $=.0000)$. We note that medium-type firms have estimated coefficients statistically no different from low-type firms.

For Product CSR, medium-type firms are less likely than low-type to have an event. However, the magnitude of the estimates are no different statistically from the high-type firms: a Wald test yields $\chi^{2}=.22$ (i.e.,p-value $=.649$ ). In short, our empirical results are consistent with our theoretical predictions; however, we cannot empirically distinguish medium- and low-type community firms from one another and we cannot distinguish high and medium-type Product CSR firms from one another. That is, if we relabeled mediumtype Product CSR firms as high-type and relabeled medium-type Community CSR firms as low-types, the empirical results would perfectly align with the baseline theory results that explore binary CSR types.

[Table 2 about here]

We also ran a Probit random-effects model, the results of which are nearly identical and can be found in Table 3. We now turn to our second primary prediction - the protection value of CSR. To do so, we utilize a financial event study. 


\section{$2.4 \quad$ Financial Event Study}

Financial event studies are a common way to quantify the financial impact of an adverse firm event. ${ }^{4}$ The particular factor model I use is the commonly used Fama/ French model (see Fama and French (1997)). Expected return in this setting is then estimated via:

$$
R_{i t}=\alpha_{i}+\beta_{i} R_{M, t}+S_{i} S M B_{t}+H_{i} H M L_{t}+\varepsilon_{i, t}
$$

That is, the return of the stock equals a firm fixed effect, plus a sensitivity to the general market return $R_{M}$, sensitivity to small stocks versus large stocks $(S M B)$, and finally a sensitivity to high versus low book to market type stocks. Coefficients are estimated from a time series just before, but disjoint, to the particular event of interest; here, following common practice, the estimation period begins 8 months prior and ends 30 days prior to the event. These coefficient estimates are then used to predict the return during the event period. That is, the predicted return around the event period becomes:

$$
\widehat{R}_{i t}=\widehat{\alpha}_{i}+\widehat{\beta}_{i} R_{M, t}+\widehat{S}_{i} S M B_{t}+\widehat{H}_{i} H M L_{t}
$$

We use this estimated returns model from the first step to predict what the expected returns are during the event of interest and then calculate the "abnormal return," defined as the difference in actual return from the predicted return: $A R_{i, t}=R_{i, t}-\widehat{R}_{i, t}$. The cumulative abnormal return is then simply the sum of these returns. For this study, we first use the day before and the day of the event announcement as our "event window." This is the most stringent of windows; we want to minimize the effect of any other previous or subsequent news confounds. We begin the window the day before, as is practice, to capture any "news leakage" the day before the event announcement. For a robustness

\footnotetext{
${ }^{4}$ For a thorough review see MacKinlay (1997). Godfrey et al. (2009) show a more recent use of the method.
} 
check, we also include 3-day and 4-day windows, where we again begin the day before the event, but then extend the window an additional 2 or 3 days from the event day, respectively. Thus our primary cumulative abnormal return is then simply:

$$
C A R_{i}=\sum_{t=-1}^{0} A R_{i, t}
$$

where 0 is the event day.

\subsection{The Impact of Incident}

Once we calculate our cumulative abnormal returns (CAR) through a financial event study on every firm facing an adverse event, our final step is to examine any relationship between the product CSR level and the respective CAR via a cross sectional regression. In particular, we specify the following:

$$
C A R_{i}=\alpha+\beta C S R_{i}+\mathbf{X}_{i} \gamma+\mathbf{Y}_{t} \boldsymbol{\delta}+\varepsilon_{i}
$$

$C A R_{i}$ is the cumulative abnormal return for firm $i$ as calculated in the previous section. The coefficients of interest are again in the vector $\boldsymbol{\beta}$, our CSR ratings.

Now we include industry controls using NAICS codes. Ideally, we would like to control at the 3-digit level. However, we only have 192 to 242 observations, depending on the specification. Hence, using 3-digit level fixed effect estimation requires close to as many coefficient estimates as observations, yielding a rather imprecise regression. Thus, for comparison, we also include analysis at the 2-digit level.

Table 4 reports these regression results using event windows of just one day, as explained in section $(2.4)$ :

[Table 4 about here] 
As predicted by our theory, high-types in Product CSR save a substantial amount of abnormal firm value upon an event-some $2.5-3.2 \%$. This effect is also economically significant, as it amounts to an average saved firm value of close to $\$ 1$ billion for the average firm experiencing an event. ${ }^{5}$ Medium-type Product CSR firms save about half of the value of a high-type firm, though the estimates are not significant at conventional levels. In contrast, high-type Community CSR firms do not seem to enjoy any protection, as predicted by theory. Interestingly, point estimates are negative, suggesting these firms are actually punished upon an event. Meanwhile, medium-type Community firms do, in fact, experience statistically significant negative abnormal returns upon an event. This is consistent with Luo et al. (2012) that find the same for the setting of oil spills: moral capital built through goodwill can cause increased damage to a firm upon a negative event. In all, this suggests our theory is missing something. How could investing in moral capital cause a reduction in firm value? It turns out that if we allow for some strategic moralcapital-building firms, these results can rationalized, which we explore in the next section.

\subsubsection{Greenwashing}

Let us now allow that there could also be some firms that make disingenuous CSR Contributions in hopes of enhancing short-term firm value. In terms of environmental CSR, this is often called greenwashing (see Lyon and Maxwell (2011) for an extended explanation). In this paper, we refer to greenwashing to mean making disingenuous CSR Contributions as opposed to disingenuous environmental CSR.

Assume that stakeholders cannot determine if CSR Contributions are genuine until after an event occurs. After an event does occur, investigations lead to information that was not publicly available before such an event. Thus, after an event, firms that have

\footnotetext{
${ }^{5}$ This is calculated as $3 \%$ of the average value of a firm experiencing an event, which is roughly $\$ 37$ billion (i.e., $.03 * 37=1.11$ ).
} 
been greenwashing are penalized (e.g., Lyon and Maxwell (2011)). This conceptualization of greenwashing can be captured in our setting by simply assuming that upon an event, greenwashing firms experience $M<0$. That is, they are penalized for having been discovered greenwashing.

Thus, we have two types of firms that make CSR Contributions: true firms and greenwash firms, denoted as $T$ and $G$, respectively. The former are those that we have modelled thus far: they enjoy reduced event cost from $M_{T}>0$, as before. In contrast, greenwash firms have reduced moral capital upon an event: $M_{G}<0$. That is, if discovered, such a firm would have been better off not greenwashing. Recall that a firm that makes no Contribution (i.e., a low-type Contribution firm) receives $M=0$.

It is then straightforward to show that upon an event, given enough greenwashing firms, those firms that invest in moral capital have on average a greater loss in firm value than those that do not invest in moral capital. That is, genuine moral capital building firms still enjoy protection, but a sufficient number of penalized greenwash firms cause the average of all firms to be negative. Further, as can be shown, as long as there are not too many greenwash firms, investing in CSR Contributions can still produce positive net present value for both greenwash and genuine CSR Contribution firms. This means that we can still witness CSR Contributions in equilibrium.

In terms of event rates, greenwash firms will have lower incident rates than genuine Contribution firms. This is because greenwash firms anticipate that if they do have an event it will be more costly, thus increasing the firm's incentive and effort to limit the chances of an event. If we assume that greenwash firms are more likely to reside in medium- rather than high-type firm categories, then we would expect to observe our empirical results: medium-type firms CSR Contribution firms should be less likely to have an event and should have a more negative event return. These two predictions are true empirically 
when comparing coefficient estimates via a Wald test for coefficient estimates reported in column (4) in Table 2 and Table 4, respectively: p-values of approximately .0000 and .06, respectively. Now we consider some alternative explanations for our baseline results.

\subsubsection{Additional Considerations}

One concern in estimating these firm value effects is that abnormal return may simply be the expected direct cost (e.g., the cost of replacing faulty automobile tires) of the product recall. If the CSR level is related with actual event cost, this in itself would be interesting, as it indicates that CSR predicts the magnitudes of firms' direct event costs. In this case, there is less room for our CSR protection story where the financial market prices a company upon an event as a function of uncertainty over the degree of negligence. Unfortunately, the expected direct cost of a product recall is seldom made public (nor is it commonly disclosed ex-post). However, for our sample, roughly $10 \%$ of the announcements were accompanied by estimates of the direct event costs. For this subsample, the direct costs explain roughly $16 \%$ of the variation in CAR. Further, when a loss is sustained by a firm (i.e., a negative CAR), the direct costs represent $38 \%$ of the total loss on average. In absolute value terms (because occasionally a firm has a positive CAR during an event), direct costs represent $26 \%$ of the value of CAR. Thus, while this sub-sample is only a small portion of the events ${ }^{6}$, it suggests that it is not the expected direct cost of an event driving differences in CAR. Further, the direct costs have a small difference in cost, whereas the change in abnormal firm value varies widely, suggesting there is much more than just product recall direct cost embedded in the CAR. Our theory suggests that the CAR should be a combination of direct recall loss and (expected) financial loss.

Another concern is that CSR ratings might simply serve as a proxy for a firm's product

\footnotetext{
${ }^{6}$ There was also no statistical difference between the observables of firms having direct costs reported and those that did not.
} 
quality and safety and thus the ratings do not really capture any notion of corporate citizenship. That is, product CSR is highly (positively) correlated with a firm's reputation for product safety. It could be that investors simply update the expected cost of the firm's event based on how safe the company's products are: the safer the products, the more likely the final cost will be less for a firm. To explore this possibility we disaggregate the regressors to include each of the eight KLD rating areas with all of the controls used in column 4 from Table 2. We find one standalone subcategory that marginally explains the differential CARs: market practices. The point estimate is -.03 with a p-value of $11 \%$. Thus, if a firm is involved in some illegal or unethical market-practice dispute (e.g., predatory pricing or collusion), it loses an additional 3\% of abnormal firm value. Meanwhile, KLD's measure of "product safety" reputation is not significant (p-value of 57\%). In all, this suggests, just as KLD claims, that their ratings have something to do with corporate citizenship and not only product safety.

For estimating the value of protection of firm value, we have used 1-day event windows. This is the strictest specification, as it minimizes the chances that a really important additional piece of news on a later day somehow contaminated the event effect. To explore this possibility, I redid all of the analysis that yielded Table 4 using a 3-day window and also a 4-day window. That is, I calculated the abnormal return as occurring from the day before until 2 and 3 days after the event day, respectively. These results are reported in Table 5 and Table 6, and as expected, are consistent with those presented in Table 4. This suggests that any new news or orthogonal shocks experienced in the immediate days following the event are not enough to (abnormally) change the value of the firm.

[Tables 5 and 6 about here]

One can also estimate what a firm should pay for such conscientiousness to see if the above estimates are reasonable. In terms of benefit, a firm moving from low-type to high- 
type via CSR Investment saves some $\$ 1$ billion of firm value conditional on an event, as shown in section (2.5). With an incident rate of .9\%, this means a risk neutral firm should be willing to pay up to $\$ 9$ million per annum more to be a higher rather than low CSR type. $^{7}$ It would be useful to compare this figure with what firms actually spend on these efforts. Unfortunately, this level of expense figures is rarely made public. However, for one example, Merck reported its 2010 annual report total spending on CSR related activities of $\$ 9.8$ million. Although this is only data from a single SP500 firm, this provides an instance in which the above estimates are reasonable. Hopefully, public disclosure of its CSR expenses will become more common, allowing us to identify actual CSR expenditures by firms in the future.

\section{Concluding discussion}

We found an explanation to the puzzle of why managers invest in CSR when it has no apparent effect on profits: Managers use CSR as a means to protect firm value. However, there are two different mechanisms scholars have proposed, which we formalized in this paper. The first and most common one is the notion that managers use CSR to build moral capital, which we termed CSR Contributions. This reservoir of goodwill can then be drawn upon should the firm face an adverse event. However, a consequence of this, which is not identified in the extant literature, is that managers will engage in moral hazard and actually increase the chances of adverse events. To the extent increased incident rates are the result of reduced managerial effort, we found this moral hazard result to be true in the data. Meanwhile, we found that if some firms are strategic and engage in greenwashing to artificially inflate valuations, such moral capital building might actually cause increased

\footnotetext{
${ }^{7}$ That is, since there is only a $.9 \%$ chance the average $\$ 1$ billion benefit will be realized in a given year, this sugests an annual benefit of $\$ 9$ million.
} 
losses in firm value upon an event. We found some suggestive empirical evidence of this, as well.

In contrast to CSR Contributions, the other proposed mechanism consists of managers investing in CSR related to a potential adverse event. For this setting, in equilibrium, those firms with higher levels of CSR related to the issue over which they face an adverse event are less likely to have been negligent. Thus, these kinds of firms both have events less often and are punished less severely upon an event. We found the data to support both of these predictions of so-called CSR Investments.

In conclusion, both of these mechanisms seem to be operating, although CSR Contributions seems to be operating in some unanticipated ways compared to the extant literature. Consequently, it is only CSR through the second mechanism that seems to provide protection, on average. 


\section{References}

[1] Baron, D.P. and D. Diermeier. (2007). Strategic Activism and Nonmarket Strategy. Journal of Economics $\&$ Management Strategy 16 (3), 599-634

[2] Baron, D. P. (2010). Morally motivated self-regulation. The American Economic Review, 100(4), 1299-1329.

[3] Capelle-Blancard, G. and Laguna, M-A. (2010) How Does the Stock Market Respond to Chemical Disasters?, Journal of Environmental Economics and Management, 59, $192-205$.

[4] Chatterji, A. K., Levine, D. I., \& Toffel, M. W. (2009). How well do social ratings actually measure corporate social responsibility? Journal of Economics $\mathcal{E}$ Management Strategy, 18(1), 125-169.

[5] Davidson, W. and D.L. Worrell. (1992). The Effect of Product Recall Announcements on Shareholder Wealth. Strategic Management Journal, 13 (6), 467-473.

[6] Elfenbein, D. W., Fisman, R., \& McManus, B. (2012). Charity as a substitute for reputation: Evidence from an online marketplace. The Review of Economic Studies, 79(4), 1441-1468.

[7] Fama, E. F., \& French, K. R. (1997). Industry costs of equity. Journal of financial economics, 43(2), 153-193.

[8] Fisher-Vanden, K. and Thorburn, K. (2011) Voluntary Corporate Environmental Initiatives and Shareholder Wealth, Journal of Environmental Economics and Management, 62, 430-445. 
[9] Fisman, R., G. Heal, and V.B. Nair. (2007). A Model of Corporate Philanthropy. Working Paper. Columbia University.

[10] Friedman, M. (1970). "The Social Responsibility of Business is to Increase its Profits." The New York Times Magazine, September 13, 1970

[11] Godfrey, P. C. (2005). The relationship between corporate philanthropy and shareholder wealth: A risk management perspective. Academy of Management Review, 30(4), 777-798.

[12] Godfrey, P.C., C.B. Merrill, and J.M. Hansen. (2009). The Relationship between Corporate Social Responsibility and Shareholder Value: An Empirical Test of the Risk Management Hypothesis, Strategic Management Journal, 30, 425-445

[13] Goyal, A. (2006). "Corporate Social Responsibility as a Signalling Device for Foreign Direct Investment." International Journal of the Economics of Business 13(1): 145163

[14] Hartman,R .S. (1987). "Product Quality and Market Efficiency The Effect of Product Recalls on Resale Prices and Firm Valuation." Review of Economics and Statistics, 6 (9), 367-72

[15] Hermalin, B. (2008). Firm value and corporate governance: Does the former determine the latter? Available at SSRN 1080090.

[16] Hillman, A. J., \& Keim, G. D. (2001). Shareholder value, stakeholder management, and social issues: what's the bottom line?. Strategic Management Journal, 22(2), 125139. 
[17] Jacobs, B.W., Singhal, V.R. and Subramanian, R. (2010). An Empirical Investigation of Environmental Performance and the Market Value of the Firm, Journal of Operations Management, 28, 430-441.

[18] Kotchen, M. J., \& Moon, J. J. (2011). Corporate social responsibility for irresponsibility (No. w17254). National Bureau of Economic Research.

[19] Luo, J., Meier, S., \& Oberholzer-Gee, F. (2012). No News is Good News CSR Strategy and Newspaper Coverage of Negative Firm Events. Harvard Business School Working Paper 12-091.

[20] Lyon, T. P., \& Maxwell, J. W. (2011). Greenwash: Corporate environmental disclosure under threat of audit. Journal of Economics $\&$ Management Strategy, 20(1), 3-41.

[21] Lyon, Thomas P., Yao Lu, Xinzheng Shi, and Qie Yin. (2013). How Do Shareholders Respond to Sustainability Awards?: Evidence from China, Ecological Economics, 2013, 94: 1-8.

[22] Mackey, A., Mackey, T. B., \& Barney, J. B. (2007). Corporate social responsibility and firm performance: Investor preferences and corporate strategies. Academy of Management Review, 32(3), 817-835.

[23] MacKinlay, C.A.. (1997). Event Studies in Economics and Finance. Journal of Economic Literature 35, 13-39.

[24] Margolis, J. D., Elfenbein, H. A., \& Walsh, J. P. (2007).Does it pay to be good? A meta-analysis and redirection of research on the relationship between corporate social and financial performance. Ann Arbor, 1001, 48109-1234.

[25] Maxwell, J.W. and C.S. Decker. (2006). Voluntary Environmental Investment and Responsive Regulation, Environmental and Resource Economics, 33, 425-439. 
[26] Maxwell, J.W., T.P. Lyon and S.C. Hackett. (2000). Self-Regulation and Social Welfare: The Political Economy of Corporate Environmentalism, Journal of Law and Economics, 43, 583-618.

[27] Minor, D.B. and J. Morgan. (2011). CSR as Reputation Insurance: Primum Non Nocere. California Management Review, 53(3), 1-20

[28] Peloza, J. (2005). Corporate Social Responsibility as Reputation Insurance. Working Paper. UC Berkeley.

[29] Ramanna, K. (2012). A Framework for Research on Corporate Accountability Reporting. HARVARD BUSINESS SCHOOL WORKING PAPER, NO. 12-021

[30] Richter, B. (2011). 'Good'and 'Evil': The Relationship Between Corporate Social Responsibility and Corporate Political Activity. working paper available at SSRN 1750368.

[31] Vogel, D. (2005). The Market for Virtue. Washington D.C.: Brookings. 


\section{Appendix: Proofs from the Text}

Lemma 1 Fix $t_{C}$. In any equilibrium, $\gamma_{L} e_{L}^{*}<\gamma_{H} e_{H}^{*}$.

Proof. We proceed by means of contradiction: suppose to the contrary that $\gamma_{L} e_{L}^{*} \geq \gamma_{H} e_{H}^{*}$. Equivalently, $\gamma_{L} e_{L}^{*} / \gamma_{H} e_{H}^{*} \geq 1$. Using equation (3) we can write

$$
\frac{\gamma_{L} e_{L}^{*}}{\gamma_{H} e_{H}^{*}}=\left(\frac{\gamma_{L}}{\gamma_{H}}\right)^{2} \frac{\rho(L) K\left(\frac{1}{M I_{t_{C}=L_{C}}+1}\right)}{\rho(H) K\left(\frac{1}{M I_{t_{C}}=H_{C}+1}\right)}
$$

and after substituting with equation (4), we obtain

$$
\frac{\gamma_{L} e_{L}^{*}}{\gamma_{H} e_{H}^{*}}=\left(\frac{\gamma_{L}}{\gamma_{H}}\right)^{2}\left\{\frac{\frac{\left(1-\gamma_{L} e_{L}^{*}\right) p_{h}}{\left(1-\gamma_{L} e_{L}^{*}\right) p_{h}+\gamma_{L} e_{L}^{*} p_{l}}}{\frac{\left(1-\gamma_{H} e_{H}^{*}\right) p_{h}}{\left(1-\gamma_{H} e_{H}^{*}\right) p_{h}+\gamma_{H} e_{H}^{*} p_{l}}}\right\} .
$$

Next, notice that the function

$$
\phi(x)=\frac{(1-x) p_{h}}{(1-x) p_{h}+x p_{l}}
$$

is strictly decreasing in $x$. Therefore, the value of the expression in the curly brackets in equation (12) is at most one. Since $\frac{\gamma_{L}}{\gamma_{H}}<1$, it then follows that the RHS equation (12) is fractional, which contradicts the hypothesis that $\gamma_{L} e_{L}^{*} / \gamma_{H} e_{H}^{*} \geq 1$.

Proposition 2 Compared with CSR Investment low-type firms, CSR Investment high-type firms have events less often and lose less value upon an event.

Proof. To ease notation, define $\operatorname{Pr}(E \mid \mathbf{t}) \equiv\left(1-\gamma_{t_{I}} e_{\mathbf{t}}\right) p_{h}+\gamma_{t_{I}} e_{\mathbf{t}} p_{l}$ and $E[C \mid \mathbf{t}] \equiv$ $\rho(\mathbf{t}) K\left(\frac{1}{M I_{t_{C}}=H_{C}+1}\right)$. Though we could solve for $e_{\mathbf{t}}^{*}$ explicitly using the quadratic formula, it is much simpler to use the fact that we always have $e_{L}^{*} \gamma_{L}<e_{H}^{*} \gamma_{H}$ in equilibrium (Lemma 1). Indeed, this inequality implies that the CSR investing firm is less likely to have an 
event. That is, it is then we have $\operatorname{Pr}(E \mid H)<\operatorname{Pr}(E \mid L)$ and $E[C \mid H]<E[C \mid L] .{ }^{8}$

Proposition 3 Compared with CSR Contribution low-type firms, CSR Contribution high-type firms have events more often and lose less value upon an event.

Proof. Holding $\gamma_{t_{I}}$ fixed, since $M>0$, a lesser $e_{\mathbf{t}}^{*}$ solves $e_{\mathbf{t}}^{*}=\gamma_{t_{I}}\left(p_{h}-p_{l}\right)\left(\rho(\mathbf{t}) K\left(\frac{1}{M I_{t_{C}=H_{C}+1}}\right)\right)$ if $I_{t_{C}=H_{C}}=1$. This implies that high-type CSR Contribution firms have a greater chance of experiencing an event since $\frac{\partial \operatorname{Pr}(E \mid \mathbf{t})}{\partial e_{t}}<0$. Thus, as opposed to the case of CSR Investments, there are opposing forces in determining the net expected cost $E[C \mid \mathbf{t}]$ upon an event. On the one hand the moral capital $M$ built helps the firm upon an event, but investors further discount the value of the firm due to the likelihood of increased negligence (i.e., a greater $\rho(\mathbf{t}))$. To see the value of moral capital $M$ dominates the negative effect of $\rho(\mathbf{t})$, we rewrite $E[C \mid t]$ as

$$
E[C \mid \mathbf{t}]=\frac{e_{\mathbf{t}}^{*}}{\gamma_{t_{I}}\left(p_{h}-p_{l}\right)}
$$

Taking the derivative with respect to $M$ yields

$$
\frac{\partial E[C \mid \mathbf{t}]}{\partial M}=\frac{1}{\gamma_{t_{I}}\left(p_{h}-p_{l}\right)} \frac{\partial e_{\mathbf{t}}^{*}}{\partial M}<0
$$

where the inequality results since $\frac{\partial e_{\mathrm{t}}^{*}}{\partial M}<0$.

\section{Appendix: KLD Accountability Reporting of CSR}

KLD forms Good and Bad CSR from the following sub-categories of analysis:

\footnotetext{
${ }^{8}$ We could add a formal calculation of the change in the present value of the firm upon an event. However, as long as the absolute event rate is low, which fits our empirical setting, adding such a feature only complicates the exposition and changes neither the results nor the intuition.
} 


\subsubsection{Product Market CSR}

Good CSR Quality: The company has a long-term, well-developed, company-wide quality program, or it has a quality program recognized as exceptional in U.S. industry.

$\mathrm{R} \& \mathrm{D} /$ Innovation: The company is a leader in its industry for research and development (R\&D), particularly by bringing notably innovative products to market.

Benefits to Economically Disadvantaged: The company has as part of its basic mission the provision of products or services for the economically disadvantaged.

Other Strengths: The company's products have notable social benefits that are highly unusual or unique for its industry.

Bad CSR Product Safety: The company has recently paid substantial fines or civil penalties, or is involved in major recent controversies or regulatory actions, relating to the safety of its products and services.

Marketing/Contracting Concern: The company has recently been involved in major marketing or contracting controversies, or has paid substantial fines or civil penalties relating to advertising practices, consumer fraud, or government contracting. (Formerly: Marketing/Contracting Controversy)

Antitrust: The company has recently paid substantial fines or civil penalties for antitrust violations such as price fixing, collusion, or predatory pricing, or is involved in recent major controversies or regulatory actions relating to antitrust allegations.

Other Concerns: The company has major controversies with its franchises, is an electric utility with nuclear safety problems, defective product issues, or is involved in other product-related controversies not covered by other KLD ratings. 


\subsubsection{Community Reputation CSR}

Good CSR Charitable Giving: The company has consistently given over 1.5\% of trailing three-year net earnings before taxes (NEBT) to charity, or has otherwise been notably generous in its giving. In 2002, KLD renamed the Generous Giving Strength as Charitable Giving.

Innovative Giving: The company has a notably innovative giving program that supports nonprofit organizations, particularly those promoting self-sufficiency among the economically disadvantaged. Companies that permit nontraditional federated charitable giving drives in the workplace are often noted in this section as well.

Non-US Charitable Giving: The company has made a substantial effort to make charitable contributions abroad, as well as in the U.S. To qualify, a company must make at least $20 \%$ of its giving, or have taken notably innovative initiatives in its giving program, outside the U.S.

Support for Housing: The company is a prominent participant in public/private partnerships that support housing initiatives for the economically disadvantaged, e.g., the National Equity Fund or the Enterprise Foundation.

Support for Education: The company has either been notably innovative in its support for primary or secondary school education, particularly for those programs that benefit the economically disadvantaged, or the company has prominently supported job-training programs for youth. In 1994, KLD added the Support for Education Strength.

Indigenous Peoples Relations: The company has established relations with indigenous peoples in the areas of its proposed or current operations that respect the sovereignty, land, culture, human rights, and intellectual property of the indigenous peoples. KLD began assigning this strength in 2000. In 2002 KLD moved this strength rating into the Human Rights area. 
Volunteer Programs: The company has an exceptionally strong volunteer program. In 2005, KLD added the Volunteer Programs Strength.

Other Strengths: The company has either an exceptionally strong in-kind giving program or engages in other notably positive community activities.

Bad CSR Investment Controversies: The company is a financial institution whose lending or investment practices have led to controversies, particularly ones related to the Community Reinvestment Act.

Negative Economic Impact: The company's actions have resulted in major controversies concerning its economic impact on the community. These controversies can include issues related to environmental contamination, water rights disputes, plant closings, "put-or-pay" contracts with trash incinerators, or other company actions that adversely affect the quality of life, tax base, or property values in the community.

Indigenous Peoples Relations: The company has been involved in serious controversies with indigenous peoples that indicate the company has not respected the sovereignty, land, culture, human rights, and intellectual property of indigenous peoples. KLD began assigning this concern in 2000. In 2002 KLD moved this strength rating into the Human Rights area.

Tax Disputes: The company has recently been involved in major tax disputes involving Federal, state, local or non-U.S. government authorities, or is involved in controversies over its tax obligations to the community. In 2005, KLD moved Tax Disputes from Corporate Governance to Community.

Other Concern: The company is involved with a controversy that has mobilized community opposition, or is engaged in other noteworthy community controversies. 
Table 1: Summary Statistics

\begin{tabular}{lrrrrr}
\hline \multicolumn{1}{c}{ Variable } & \multicolumn{1}{l}{ Obs } & \multicolumn{1}{l}{ Mean } & \multicolumn{1}{l}{ Std. Dev. } & \multicolumn{1}{l}{ Min } & \multicolumn{1}{l}{ Max } \\
\hline Cumulative Abnormal Return (CAR) & 242 & -0.007 & 0.066 & -0.369 & 0.492 \\
Event (Indicator) & 26585 & 0.009 & 0.095 & 0.000 & 1.000 \\
High Product CSR & 26586 & 0.070 & 0.256 & 0.000 & 1.000 \\
High Community CSR & 26586 & 0.132 & 0.339 & 0.000 & 1.000 \\
Medium Product CSR & 26586 & 0.738 & 0.440 & 0.000 & 1.000 \\
Medium Community CSR & 26586 & 0.796 & 0.403 & 0.000 & 1.000 \\
Market Value (millions) & 26498 & 6501.489 & 23239.860 & 0.000 & 626550.400 \\
Market to Book & 26458 & 2.135 & 1.471 & 1.000 & 27.716 \\
Leverage & 25689 & 0.209 & 0.195 & -0.010 & 4.910 \\
Year & & & & & \\
\hline
\end{tabular}


Table 2: Event Rates and levels of CSR (Logit)

\begin{tabular}{lcccc}
\hline & Dependent Variable: Event & & \\
& $(1)$ & $(2)$ & $(3)$ & $(4)$ \\
\hline High Product CSR & $-1.0447^{* * *}$ & $-0.9153^{* * *}$ & $-0.9994^{* * *}$ & $-0.8696^{* *}$ \\
& $(-3.18)$ & $(-2.77)$ & $(-2.90)$ & $(-2.53)$ \\
High Community CSR & & & & \\
& $0.7313^{* *}$ & $0.8345^{* * *}$ & $0.9670^{* * *}$ & $0.8742^{* *}$ \\
& -2.46 & -2.73 & -2.77 & -2.51 \\
Medium Product CSR & & & & \\
& $-1.3278^{* * *}$ & $-1.1978^{* * *}$ & $-1.1519^{* * *}$ & $-1.0268^{* * *}$ \\
Medium Community CSR & $(-6.30)$ & $(-5.51)$ & $(-5.01)$ & $(-4.51)$ \\
& & & & \\
& -0.4427 & -0.3501 & -0.3076 & -0.2791 \\
Observations & $(-1.51)$ & $(-1.15)$ & $(-0.88)$ & $(-0.80)$ \\
Log Likelihood & & & & \\
Year Fixed Effects & 26581 & 25620 & 25498 & 25498 \\
Financial Controls & -909.2426 & -844.7997 & -685.9662 & -656.6200 \\
Industry Controls (NAICS) & & & & \\
\hline & Yes & Yes & Yes & Yes \\
t statistics in parentheses & No & Yes & Yes & Yes \\
& No & No & 2 digit & 3 digit \\
\hline
\end{tabular}


Table 3: Event Rates and Levels of CSR (Probit)

\begin{tabular}{|c|c|c|c|c|}
\hline & \multicolumn{2}{|c|}{ Dependent Variable: Event } & \multirow[b]{2}{*}{ (3) } & \multirow[b]{2}{*}{ (4) } \\
\hline & (1) & $(2)$ & & \\
\hline High Product CSR & $\begin{array}{c}-0.4856^{* * *} \\
(-3.20)\end{array}$ & $\begin{array}{c}-0.4547^{* * *} \\
(-2.93)\end{array}$ & $\begin{array}{c}-0.4931 * * * \\
(-3.10)\end{array}$ & $\begin{array}{c}-0.4346^{* * *} \\
(-2.71)\end{array}$ \\
\hline High Community CSR & $\begin{array}{c}0.3816^{* * *} \\
(2.65)\end{array}$ & $\begin{array}{c}0.4299 * * * \\
(2.91)\end{array}$ & $\begin{array}{c}0.4966^{* * *} \\
(2.97)\end{array}$ & $\begin{array}{c}0.4483 * * * \\
(2.67)\end{array}$ \\
\hline Medium Product CSR & $\begin{array}{c}-0.6267^{* * *} \\
(-6.45)\end{array}$ & $\begin{array}{c}-0.5673 * * * \\
(-5.63)\end{array}$ & $\begin{array}{c}-0.5606 * * * \\
(-5.29)\end{array}$ & $\begin{array}{c}-0.5020 * * * \\
(-4.73)\end{array}$ \\
\hline Medium Community CSR & $\begin{array}{c}-0.1769 \\
(-1.26)\end{array}$ & $\begin{array}{l}-0.1295 \\
(-0.89)\end{array}$ & $\begin{array}{c}-0.0893 \\
(-0.54)\end{array}$ & $\begin{array}{c}-0.0830 \\
(-0.50)\end{array}$ \\
\hline Observations & 26581 & 25620 & 25498 & 25498 \\
\hline Log Likelihood & -906.4960 & -840.3725 & -679.8645 & -651.6976 \\
\hline Year Fixed Effects & Yes & Yes & Yes & Yes \\
\hline Financial Controls & No & Yes & Yes & Yes \\
\hline Industry Controls (NAICS) & No & No & 2 digit & 3 digit \\
\hline
\end{tabular}


Table 4: Magnitude of Firm Value Protection and Levels of CSR (1 day window)

\begin{tabular}{|c|c|c|c|c|}
\hline & \multicolumn{2}{|c|}{ Dependent Variable: Event } & \multirow[b]{2}{*}{ (3) } & \multirow[b]{2}{*}{ (4) } \\
\hline & (1) & $(2)$ & & \\
\hline \multirow[t]{2}{*}{ High Product CSR } & $0.0244^{* *}$ & $0.0311^{* * *}$ & $0.0324^{* *}$ & $0.0249 *$ \\
\hline & (2.49) & $(2.70)$ & $(2.50)$ & (1.91) \\
\hline \multirow[t]{2}{*}{ High Community CSR } & -0.0130 & $-0.0242 *$ & -0.0250 & -0.0245 \\
\hline & $(-0.93)$ & $(-1.75)$ & $(-1.29)$ & $(-1.22)$ \\
\hline \multirow[t]{2}{*}{ Medium Product CSR } & 0.0097 & 0.0157 & 0.0155 & 0.0128 \\
\hline & $(1.10)$ & (1.38) & $(1.22)$ & $(0.93)$ \\
\hline \multirow[t]{2}{*}{ Medium Community CSR } & $-0.0260 *$ & $-0.0352^{* *}$ & $-0.0454^{* *}$ & $-0.0461 * *$ \\
\hline & $(-1.69)$ & $(-2.32)$ & $(-2.08)$ & $(-2.20)$ \\
\hline Observations & 242 & 228 & 192 & 192 \\
\hline R Squared & 0.092 & 0.169 & 0.215 & 0.291 \\
\hline Year Fixed Effects & Yes & Yes & Yes & Yes \\
\hline Financial Controls & No & Yes & Yes & Yes \\
\hline Industry Controls (NAICS) & No & No & 2 digit & 3 digit \\
\hline
\end{tabular}


Table 5: Magnitude of Firm Value Protection and Levels of CSR (3 day window)

\begin{tabular}{|c|c|c|c|c|}
\hline & \multicolumn{2}{|c|}{ Dependent Variable: Event } & \multirow[b]{2}{*}{ (3) } & \multirow[b]{2}{*}{ (4) } \\
\hline & (1) & $(2)$ & & \\
\hline \multirow[t]{2}{*}{ High Product CSR } & 0.0177 & 0.0237 & $0.0279 *$ & 0.0216 \\
\hline & $(1.20)$ & $(1.46)$ & (1.67) & $(1.30)$ \\
\hline \multirow[t]{2}{*}{ High Community CSR } & -0.0090 & $-0.0268 *$ & -0.0314 & -0.0288 \\
\hline & $(-0.48)$ & $(-1.71)$ & $(-1.46)$ & $(-1.26)$ \\
\hline \multirow[t]{2}{*}{ Medium Product CSR } & 0.0144 & 0.0205 & 0.0168 & 0.0161 \\
\hline & $(1.30)$ & $(1.53)$ & $(1.06)$ & $(0.96)$ \\
\hline \multirow[t]{2}{*}{ Medium Community CSR } & -0.0327 & $-0.0473 * * *$ & $-0.0607 * *$ & $-0.0628 * * *$ \\
\hline & $(-1.59)$ & $(-2.68)$ & $(-2.51)$ & $(-2.66)$ \\
\hline Observations & 242 & 228 & 192 & 192 \\
\hline R Squared & 0.093 & 0.169 & 0.211 & 0.280 \\
\hline Year Fixed Effects & Yes & Yes & Yes & Yes \\
\hline Financial Controls & No & Yes & Yes & Yes \\
\hline Industry Controls (NAICS) & No & No & 2 digit & 3 digit \\
\hline
\end{tabular}


Table 6: Magnitude of Firm Value Protection and Levels of CSR (4 day window)

\begin{tabular}{|c|c|c|c|c|}
\hline & \multicolumn{2}{|c|}{ Dependent Variable: Event } & \multirow[b]{2}{*}{ (3) } & \multirow[b]{2}{*}{ (4) } \\
\hline & (1) & $(2)$ & & \\
\hline \multirow[t]{2}{*}{ High Product CSR } & $0.0257 * *$ & $0.0322 * *$ & $0.0314^{* *}$ & $0.0270^{*}$ \\
\hline & $(2.14)$ & $(2.37)$ & $(2.11)$ & (1.91) \\
\hline \multirow[t]{2}{*}{ High Community CSR } & -0.0149 & $-0.0297^{*}$ & -0.0307 & -0.0287 \\
\hline & $(-0.88)$ & $(-1.93)$ & $(-1.48)$ & $(-1.30)$ \\
\hline \multirow[t]{2}{*}{ Medium Product CSR } & 0.0107 & 0.0163 & 0.0156 & 0.0144 \\
\hline & $(1.10)$ & $(1.33)$ & (1.09) & $(0.97)$ \\
\hline \multirow[t]{2}{*}{ Medium Community CSR } & $-0.0358 * *$ & $-0.0489 * * *$ & $-0.0622 * * *$ & $-0.0642 * * *$ \\
\hline & $(-1.97)$ & $(-2.99)$ & $(-2.71)$ & $(-2.83)$ \\
\hline Observations & 242 & 228 & 192 & 192 \\
\hline R Squared & 0.072 & 0.162 & 0.210 & 0.268 \\
\hline Year Fixed Effects & Yes & Yes & Yes & Yes \\
\hline Financial Controls & No & Yes & Yes & Yes \\
\hline Industry Controls (NAICS) & No & No & 2 digit & 3 digit \\
\hline
\end{tabular}


Figure 1: A Probability Tree for the Likelihood of Firm Events

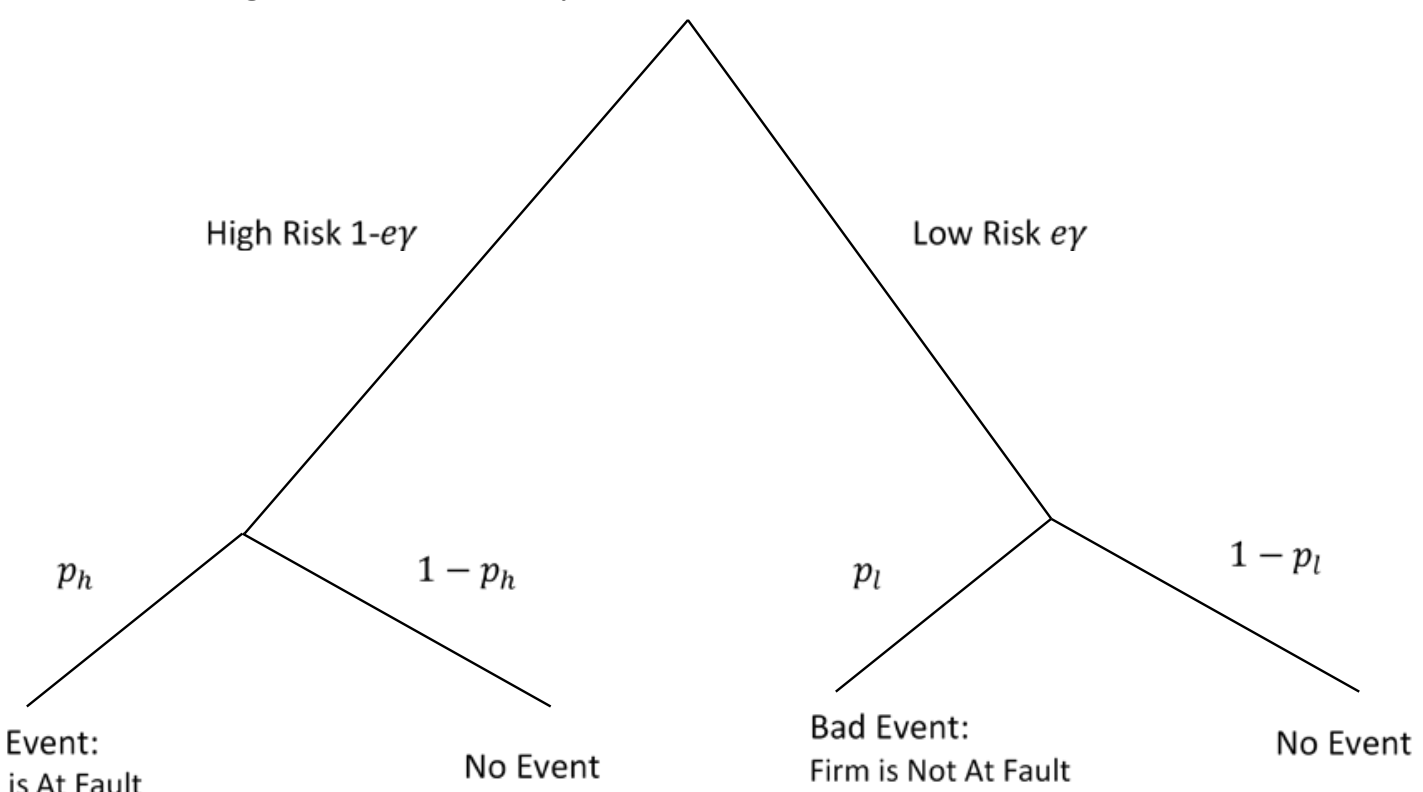

Bad Event:

Firm is At Fault

Firm is Not At Fault

Firm effort is $e$, firm type is $\gamma$, and $p_{h}$ and $p_{l}$ are the probability of the firm in a high and low risk state experiencing an event, respectively. 